\title{
STUDIES ON RED BLOOD CELL DIAMETER ${ }^{1}$
}

\author{
II. In Pernicious Anemta, Before and During Marked \\ Remission, AND IN Myelogenous Leukemia
}

By DONALD N. MEDEARIS AND GEORGE R. MINOT

(From the Medical Service of the Collis P. Huntington Memorial Hospital of Harvard University and the Medical Clinic of the Peter Bent Brigham.Hospital)

(Received for publication August 6, 1926)

\section{INTRODUCTION}

Since Leeuwenhoek's discovery of the human red blood corpuscles in 1673, he and many investigators have reported observations concerning their average diameter. It remained for Price-Jones (1) in 1910 to reawaken interest in such measurements by pointing out their clinical value when obtained by his simple technic and studied in a statistical manner. His (1) (2) (3) observations have been confirmed by numerous physicians (4) (5) (6) (7) and have shown that data plotted for the diameters of the red blood cells in pernicious anemia in relapse give a very wide percentage frequency curve as compared to that for normal red blood corpuscles. This indicates abnormal variation in the size of the cells. The well-known fact that the average red blood cell size is distinctly greater than normal in cases of pernicious anemia with a low red blood cell count, also is emphasized by these measurements. It appears to be quite generally believed that these changes in the red blood corpuscles are present, although to a lesser degree, before the patient becomes obviously anemic and during remissions of the disease. Except for one case recorded by Price-Jones (3) with a red blood cell count of 4,400,000 per cubic millimeter, however, no data have been found in the literature concerning actual measurements of the diameters of the red blood cells when their numbers, after being distinctly few, have

${ }^{1}$ Study No. I: In health and pernicious anemia. Bell, J. R., Thomas, J. K., and Means, J. H. Jour. Clin. Invest.. 1926, iii, 229. 
increased to above $4,200,000$ per cubic millimeter. Price-Jones (2) (3), Grosh and Stifel (6), and others have studied the cell diameter during remissions, but they usually have referred only to high values for hemoglobin percentage, and not to the red blood cell count. When the latter have been recorded it has been below 4,200,000 per cubic millimeter except in Price-Jones' case. These investigators found that during the remissions of their cases, although the cell size approached toward the normal, the data obtained showed that the changes in cell size typical of pernicious anemia still persisted to some degree.

We have made an investigation of the size of the red blood cells in seventeen selected cases of pernicious anemia with red blood cell counts which were low at one time but later increased, reaching in fourteen instances 4,200,000 or more per cubic millimeter. As it was thought that some cases of myelogenous leukemia might show a red blood cell picture like that of pernicious anemia in relapse, a study also was undertaken of the cell size in eleven cases of myelogenous leukemia.

\section{TECHNIC AND CONTROL}

The technic used to measure the size of the red blood cells was a modification of Price-Jones' method described in the first paper of the present series (7). The cells in fixed stained blood films were measured directly by means of an ocular micrometer calibrated so that measurements to every 0.625 micron could be obtained. Two hundred and fifty cells were measured for each observation recorded. From the data obtained both percentage frequency and summation frequency curves were plotted in the manner described by Bell, Thomas and Means (7) and as shown in figures 1 and 2. The median diameter is not the same as the average or mean diameter, but is the figure for the 50 percentile grade of the summation frequency curve plotted on arithmetic probability paper, and represents the center of the range of distribution of the red blood cell diameters. Thus, there are as many cells larger in diameter than the median as there are smaller in diameter. The dispersion of the red blood cell diameters is the difference between those for the 84 and the 16 percentile grades of the summation frequency curve, and indicates quantitatively the amount of anisocytosis. 
Measurements were made of 2750 red blood cells in eleven preparations from six healthy individuals. The data so obtained served as a control. The average mean diameter of the normal cells was 7.55 microns, with a mean deviation in this value for the cells of the eleven smears of only \pm 0.16 micron. The average median diameter was 7.50 microns; and the average dispersion was 1.17 micron. The normal extremes for these values were: (a) Mean diameter from 7.25 to 7.75 microns; $(b)$ median diameter from 7.25 to 7.75 microns; (c) dispersion from 1.00 to 1.30 micron; (d) the range of the diameters of the 2750 cells was from 5.2 to 10.0 microns. These results are comparable to those recorded by others and are in close agreement with the range for normal values obtained by Bell et al. (7). These latter authors found both the normal average mean and the median diameter to be 7.70 microns, with extremes of 7.4 and 8.0 microns. The average dispersion of the normal cells they studied was 1.10 micron, with a variation of from 1.00 to 1.20 micron, and the diameters varied from 5.30 to 9.90 microns.

\section{PERNICIOUS ANEMIA}

Fourteen of the seventeen patients with typical pernicious anemia showed increases of red blood cell counts to $4,200,000$ or more per cubic millimeter and will be particularly referred to. They improved markedly in health while taking the special diet recommended by Minot and Murphy (8) and are included in their series of 45 cases. The diet is one particularly rich in liver, contains an abundance of muscle meat, fruits, and green vegetables, and is sparing in fat. Two of the other three patients had had this diet for some weeks and their cells were measured then, when their counts were just below $4,000,000$ per cubic millimeter. The last case to be recorded had a remission following no especial form of therapy.

Measurements have been made of the red blood corpuscles in eleven of the fourteen cases, both when their count was low and when it had risen to between $4,200,000$ and $6,350,000$ per cubic millimeter. The cells were measured in the other three cases when the red blood cell counts were over $5,000,000$ per cubic millimeter but measurements could not be made when the counts were low as the preparations had been destroyed before this study was begun. However, it is 
544. RED BLOOD CELL DIAMETER IN PERNICIOUS ANEMIA

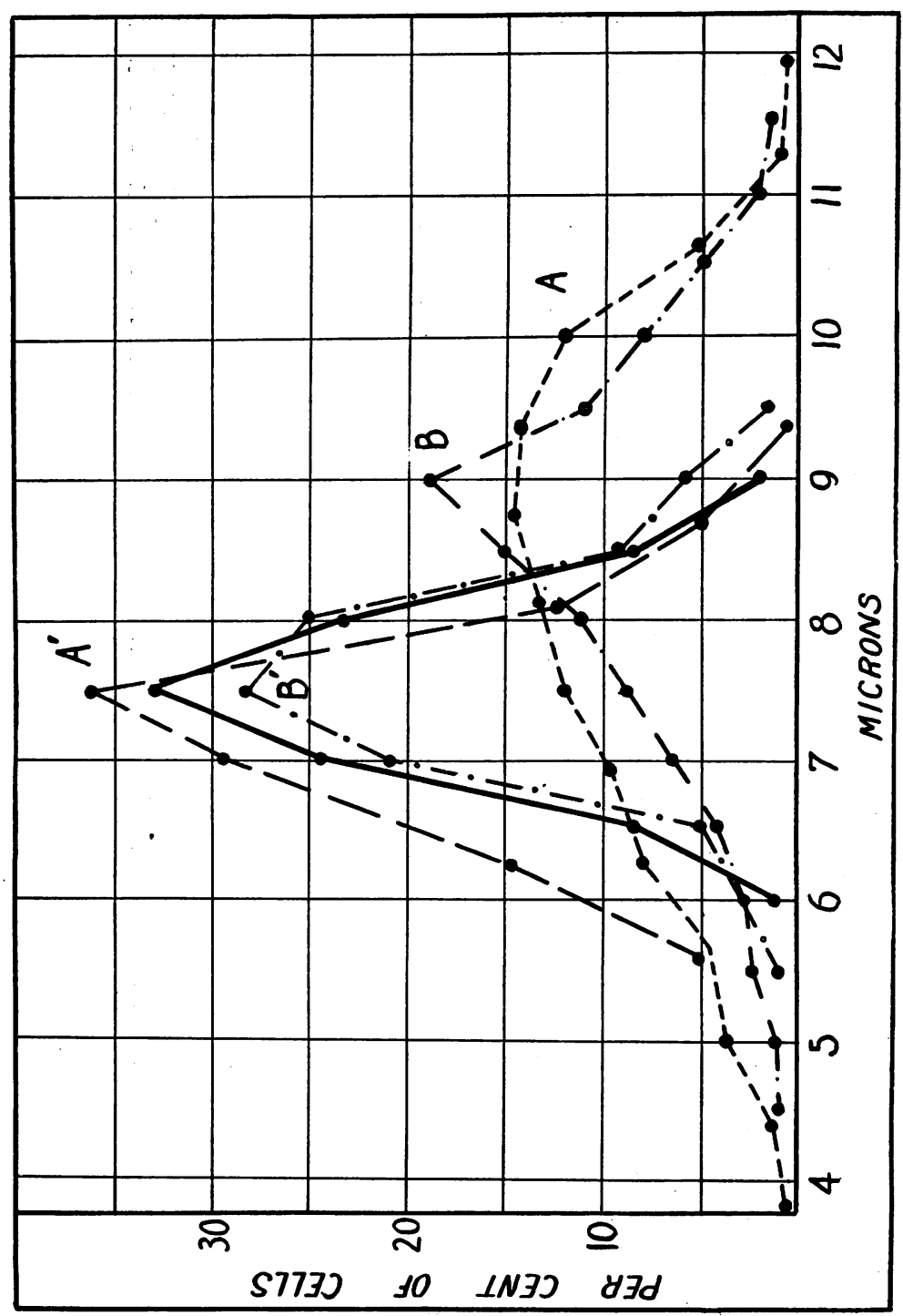

$\stackrel{\circ}{3}$

吕

㚬

为

คㅇํㅇ

คै

公曷

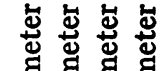

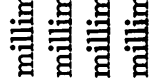

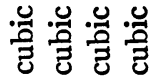
苍芯 范

营

용 8

装

용ㅇㅇ 용

थ

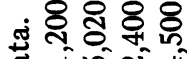

चौ कीले

실

A $\leq$

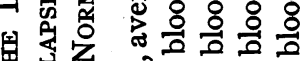

焉Z

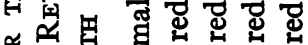

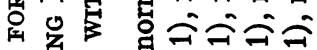

路

号

厂잉웡

蛋焉

$\sim N N N$

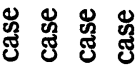

它究

爷

กิ?

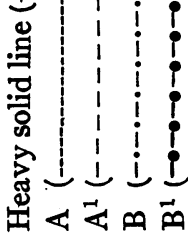


known that when the red blood cell counts of these three patients were low, the cells showed all the features characteristic of a relapse in pernicious anemia.

TABLE 1

The diameters of red blood corpuscles in pernicious anemia during relapse contrasted with their diameters during marked remission

\begin{tabular}{|c|c|c|c|c|c|c|c|c|c|c|c|}
\hline \multirow[b]{2}{*}{ Case } & \multirow{2}{*}{ 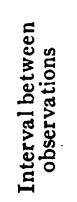 } & \multicolumn{2}{|c|}{$\begin{array}{l}\text { Red blood } \\
\text { cells }\end{array}$} & \multicolumn{2}{|c|}{$\begin{array}{c}\text { Mean } \\
\text { diameter }\end{array}$} & \multicolumn{2}{|c|}{$\begin{array}{c}\text { Median } \\
\text { diameter }\end{array}$} & \multicolumn{2}{|c|}{$\begin{array}{c}\text { Smallest ard g-eatest } \\
\text { diameter }\end{array}$} & \multicolumn{2}{|c|}{ Dispersion } \\
\hline & & 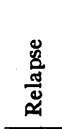 & 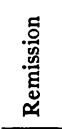 & 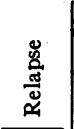 & 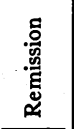 & 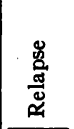 & 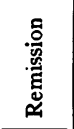 & 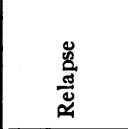 & 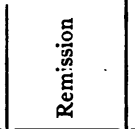 & 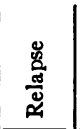 & 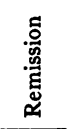 \\
\hline & months & $\begin{array}{l}\text { mil- } \\
\text { lions }\end{array}$ & $\begin{array}{l}\text { mil- } \\
\text { lions }\end{array}$ & $\underset{\text { crons }}{m i-}$ & $\underset{\substack{m i-\\
\text { crons }}}{\text { mat }}$ & $\begin{array}{l}\text { mi- } \\
\text { crons }\end{array}$ & $\begin{array}{l}\text { mi- } \\
\text { crons }\end{array}$ & microns & microns & $\underset{\text { crons }}{m i-}$ & $\begin{array}{c}m i- \\
\text { crons }\end{array}$ \\
\hline 1 & 9 & 1.1 & 4.2 & 8.70 & 7.57 & 9.10 & 7.71 & $3.7-13.0$ & $6.3-10.0 \mid$ & 3.80 & 1.24 \\
\hline 2 & 20 & 2.4 & 4.4 & 8.43 & 7.62 & 8.71 & 7.69 & $4.0-10.0$ & $|5.5-9.5|$ & 2.54 & 1.34 \\
\hline $3^{*}$ & 7 & 3.7 & 5.1 & 8.16 & 7.44 & 8.18 & 7.43 & $5.6-10.0$ & $5.5-9.5$ & 1.87 & 1.25 \\
\hline & 2 & 3.0 & 4.2 & 8.44 & 7.46 & 8.43 & 7.43 & $6.2-10.0$ & $5.6-10.0 \mid$ & 1.57 & 1.32 \\
\hline & 14 & & 5.0 & & 7.43 & & 7.44 & & $6.3-8.8$ & & 0.96 \\
\hline 5 & 7 & 2.8 & 4.5 & 8.30 & 7.26 & 8.00 & 7.31 & $3.0-13.0$ & $|5.0-8.8|$ & 2.04 & 1.00 \\
\hline 6 & 2 & 2.6 & 4.8 & 8.50 & 7.62 & 8.43 & 7.61 & $4.4-11.9$ & $5.6-10.0 \mid$ & 2.07 & 1.50 \\
\hline 7 & 4 & 1.2 & 5.0 & 8.23 & 7.24 & 8.31 & 7.25 & $3.8-12.5$ & $|5.0-9.4|$ & 3.37 & 1.33 \\
\hline 8 & 3 & 1.8 & 5.1 & 7.98 & 7.40 & 7.93 & 7.44 & $5.0-11.3$ & $|5.6-9.4|$ & 2.00 & 1.30 \\
\hline 9 & 2 & 2.0 & 5.5 & 7.93 & 6.81 & 7.87 & 6.81 & $5.6-11.3$ & $|5.0-8.8|$ & 2.12 & 1.25 \\
\hline $10 \ddagger$ & 2 & 3.2 & 6.4 & $7.4 \mathrm{C}$ & 7.23 & 7.46 & 7.25 & $5.0-9.4$ & $|5.6-8.8|$ & 1.70 & 1.06 \\
\hline $11 \S$ & 5 & 1.5 & 5.4 & 7.84 & 7.25 & 7.77 & 7.31 & $4.0-11.25$ & $|5.0-9.4|$ & 2.65 & 1.25 \\
\hline 12 & 7 & 1.3 & 6.3 & ๆ & 7.34 & ๆ & 7.31 & T & $|5.0-10.6|$ & $\pi$ & 1.25 \\
\hline 13 & 7 & 2.2 & 6.1 & I & 7.19 & ๆ & 7.19 & ๆ & $|5.6-10.4|$ & T & 1.11 \\
\hline 14 & 2 & 0.9 & 5.3 & ๆ & 7.08 & ๆ & 7.09 & T & $|5.6-8.8|$ & T & 1.10 \\
\hline Average & 5 & 2.1 & 5.2 & 8.17 & 7.33 & 8.19 & 7.35 & $4.7-11.3$ & $|5.5-9.5|$ & 2.34 & 1.22 \\
\hline
\end{tabular}

* Previously the red blood cell count had been about 1,500,000 per cubic millimeter.

$\dagger$ The lower figures (4b) are those for measurements made after patient had remained in marked remission for one year.

$\ddagger$ Previously macrocytosis had been marked. Liver had been eaten daily for seven weeks before first measurements were made.

\$ At time of relapse, there were so many small cells that the values for the average diameter and median were less than is usual in pernicious anemia with low red blood cell counts. However, there is a high dispersion.

II Measurements were not made. The cells showed a distinct macrocytosis. Microcytes were plentiful and anisocytosis marked.

Table 1 summarizes the data concerning the red blood cell size of the fourteen cases. In every case during the marked remissions, 


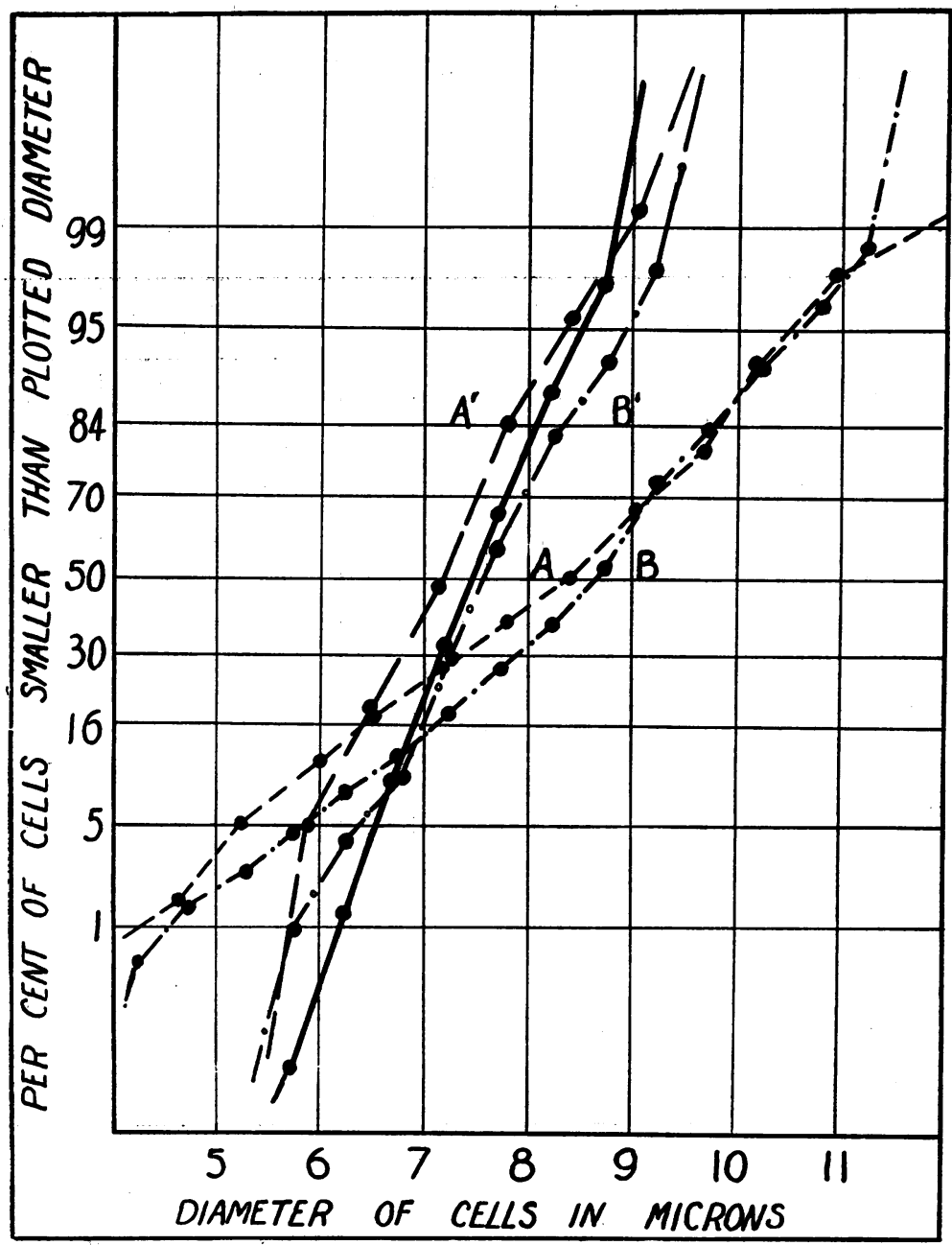

Fig. 2. Summation Frequency Curves Plotted on Arithmetic Probability Paper for the Diameters of the Red Blood Cells in the Same Two Cases of Pernicious Anemia for Which Percentage Frequency Curves are GIVEN IN Figure 1

Solid line (-) normal, averaged data.

A (------) case 7 (table 1), red blood cells $1,200,000$ per cubic millimeter $\mathrm{A}^{1}\left(---_{---}\right)$case 7 (table 1), red blood cells 5,020,000 per cubic millimeter B (-.-.-.-.-.-.) case 2 (table 1 ), red blood cells $2,400,000$ per cubic millimeter $\mathrm{B}^{1}(\longrightarrow \rightarrow-\longrightarrow \rightarrow)$ case 2 (table 1 ), red blood cells $4,500,000$ per cubic millimeter 
the values of the mean and median diameters of the red blood cells, which are abnormally high in pernicious anemia during a definite relapse, were found below the upper normal limits. During remission the dispersion was found distinctly above normal (1.5 micron) only in case 6 . In all but three of the other cases it was 1.3 micron or less. In these three cases $(2,4 a, 7)$ it was between 1.32 and 1.34 micron, or just above the upper limit ( 1.3 micron) for the normal red blood cells that we studied. In one of these cases (no. 4), however, the dispersion later became even less than normal ( 0.96 micron). In addition to this latter case, four others had a dispersion of less than 1.2 micron, the upper normal limit given by Bell, Thomas and Means (7). Thus, in spite of normal median and mean diameters there was a tendency for the dispersion to be a little above normal, but certainly five cases had a dispersion of their red blood cell diameters well below the upper normal limit.

Indeed, not only did the cells in most of these fourteen cases return to normal size, but in three (cases 9,13, and 14) their mean diameter fell distinctly below normal. In four others (cases $5,7,10,11$ ), it was close to the lower normal limit. Thus the curves for the diameters of the red blood cells from these cases simulated those in chronic anemia due to blood loss and other so-called secondary anemias, except that the dispersions showed a greater tendency to remain within normal limits.

Figure 1 illustrates graphically by percentage frequency curves, and figure 2 by summation frequency curves, the diameters of the cells in two typical cases of pernicious anemia in relapse (cases 2 and 7 of table 1), and during remissions when there was a return of the diameters essentially or actually to normal proportions. The figures in table 1 and curves of figure 1 for the diameters of the cells when their count was distinctly low, are quite like those recorded by others as typical of pernicious anemia in relapse.

In the eleven cases for which measurements are recorded both before and during marked remission, it is noteworthy that in each case there was a uniform lowering of the mean and the median diameter and of the dispersion. The change in the figures for the diameters was often marked, and average figures for all cases, when the red blood cell counts were low and high, as shown at the bottom 
of table 1, are in striking contrast. It, thus, is evident that in marked remissions of pernicious anemia the size of the red blood corpuscles can become normal. Therefore, curves for the diameters of the red blood cells are not of diagnostic value in. all stages of pernicious anemia, as concluded by Grosh and Stifel (6) and others (3) (4) (5) who have measured the red blood cells in this disease.

Data recorded in table 1 together with that given by Price-Jones (3) and others indicate that when the red blood cell count in pernicious anemia is between about $3,000,000$ and $4,000,000$ per cubic millimeter, although the red blood cell picture approaches normal it still retains some features typical of the disease. Two of our three patients who had received the special diet for only a few weeks and who are not included among the fourteen cases referred to above, showed, when their red blood cell count had risen to just below 4,000,000 per cubic millimeter, an abnormally large average diameter of their red blood cells; namely, 8.47 microns and 8.49 microns. The change to normal sized red blood cells, however, frequently appears to take place when the count increases somewhat above $4,000,000$ per cubic millimeter; and, as it rises still higher, the average diameter of the cells may become smaller than normal.

Although the diameters of the red blood cells in cases of pernicious anemia with high red blood cell counts may not simulate those found during a relapse, this fact does not invalidate the method, in general, for diagnosis. The procedure is useful in helping to establish a diagnosis of pernicious anemia, for the patient with this disease seldom consults a physician until his red blood cell count is below 4,000,000 per cubic millimeter, and therefore at a time when the average diameter of the cells is large and when frequency curves of their diameters at least suggest pernicious anemia.

The fact that the patients with pernicious anemia who partook of the special diet, rich in liver, showed a decrease even below normal in the mean diameter of their red blood corpuscles-a finding which was associated with a decreased color index (to be discussed in a paper by Dr's. W. P. Murphy, R. Fitz, and R. D. Monroe)-stimulates speculation. Is it possible that there is some factor in this diet which maturates and produces cells at a greater rate than normal so that the size of the cells is diminished? One also wonders if patients with 
pernicious anemia who have so-called spontaneous remissions show cells of such small size. Probably they may do so, but we have had no opportunity to measure the cells from such a case with a distinctly high red blood cell count. The blood from one case in a spontaneous remission of over four months' duration was studied then, when the red cell count was $3,900,000$ per cubic millimeter, and the hemoglobin 85 per cent. The mean diameter of these red blood cells was 7.77 microns, the median 7.75 microns; the diameters ranged from 6.25 to 10.0 microns, and the dispersion was 1.47 micron. Thus, these cells varied in size a little more than the normal, but their mean and median diameters were near the upper normal limits.

\section{MYELOGENOUS LEUKEMIA}

Very few measurements of the diameters of the red blood corpuscles in leukemia are recorded in the literature. Hampson and Shackle (5) state that one of three cases of "aleukemic leukemia" which they studied showed a curve for the diameter of the red blood corpuscles that was typical "for the megalocytic sort of anemia." They looked for, but never observed, this picture in chronic myelogenous leukemia.

Nine of the eleven cases of myelogenous leukemia, in which we studied the red blood cell diameter, were typical of the chronic type and showed the usual leukemic bood picture, while two were cases of subacute myelogenous leukemia, presenting an aleukemic blood picture at the time our observations were made. The former cases were treated over a period of from one to four years with roentgen-rays or radon, but no measurements of cell diameters were made in any case until the patient had remained untreated for at least four weeks and usually much longer. The two subacute cases were given no roentgen-rays or radon. Measurements of the red blood cell diameters were made two to nine times in each case at intervals of weeks to months. The observations on most of the chronic cases extended over a period of two to three years. In each of the subacute cases only two observations were made, and these within a few weeks of death.

The mean diameter of the red blood cells in eight of the nine chronic cases and one of the two subacute aleukemic cases was, on nearly every observation, either definitely below normal or close to the lower 
normal limit: on the average about 7.10 microns and usually varying but little in each case as time passed by. The dispersion was almost always definitely increased on every examination for each case, the average figure being 1.57 micron, and the variations lying between 1.25 and 1.90 micron. In brief, the red blood cell picture was that typical of so-called secondary anemia. In two of these cases, as death approached, there was a progressive decrease in the mean diameter of the cells; in one from 7.37 to 6.94 microns, and in the other from 7.33 to 6.56 microns. The decrease in the latter case could be attributed to chronic loss of blood associated with a marked decrease in the blood platelets. There also occurred at this time many very small myeloblasts in the blood stream. In two of the other cases there developed a terminal increase in the mean diameter of the red blood cells, and this was accompanied by a rather pronounced increase in the dispersion, which rose to 1.9 micron. The mean diameter, however, never rose above the average for normal cells.

The red blood cells of one patient with chronic myelogenous leukemia were measured in preparations obtained on seven different occasions over a period of two and one-half years, and their mean diameter was always found close to 7.50 microns, which was greater than the figure observed at any time in the other chronic cases. During the following four months measurements showed that the mean diameter of this patient's red blood cells was increased distinctly above normal, reaching 8.15 microns at three months, and 8.50 microns at three weeks before death. The percentage frequency curves for the diameters of the cells from this patient, two and onehalf years before, and again three weeks before death are shown in figure 3. The dispersion of the cell diameters prior to the time their mean diameter enlarged averaged 1.50 micron; and when their mean diameter increased, the degree of dispersion also rose to between 1.80 and 1.90 micron. One of the two cases of subacute myelogenous leukemia also showed, a few weeks before death, a macrocytosis of the red blood corpuscles. Their diameters varied from 5.5 to 11.25 microns with a mean diameter of 8.3 microns, and a median diameter of 8.5 microns, while the dispersion was 1.5 micron.

As the mean diameter of the red blood corpuscles increased above 
normal in the chronic case, the nucleated bone marrow cells present in the peripheral blood became not only more immature in type, but also more atypical or abortive in character, although the white blood cell count remained about 70,000 per cubic millimeter. Similar cells in the subacute case formed the majority of the 5,000 white blood cells per cubic millimeter present in the peripheral blood.

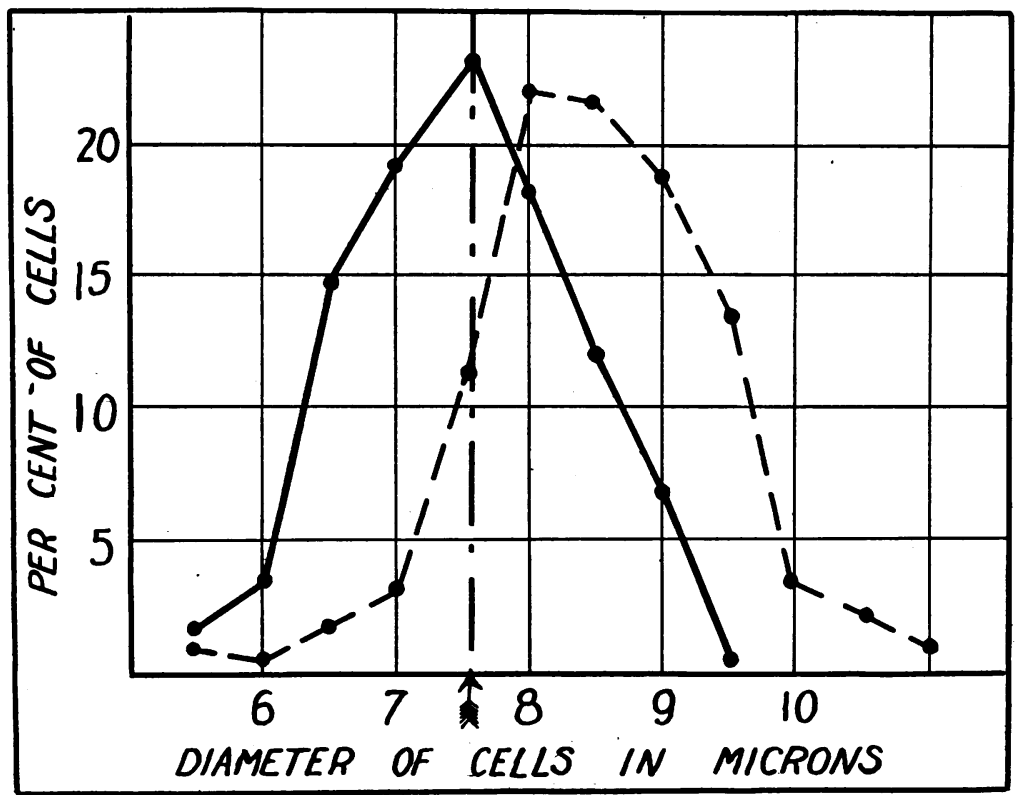

Fig. 3. Case of Chronic Myelogenous leukemia that Developed MacROCYTOSIS OF THE RED -BLOOD CELLS

Solid line (-) red blood corpuscle diameters, two and one half years before death of patient.

Dotted line $(\ldots \ldots \ldots)$, red blood corpuscle diameters three weeks before death of patient.

Arrow marks the locus on the curve of the averaged mean diameter for normal red blood cells.

A variety of cases with absence of free hydrochloric acid in the gastric contents, other than pernicious anemia, have shown macrocytosis of their red blood corpuscles (7). Thus one may wonder if an achlorhydria occurred in the two cases of leukemia that showed an increase in the average diameter of their red blood cells. It is known 
that the patient with subacute leukemia had free hydrochloric acid in each of several specimens of gastric contents obtained after a test meal. There was no gastric analysis made in the chronic case. In both these cases of leukemia, during the latter part of the disease, the red blood cell picture simulated that of pernicious anemia in relapse, though our studies show that such a picture is not the rule in myelogenous leukemia.

\section{SUMMARY}

The mean and median diameter of the red blood cells in pernicious anemia may become normal (observed in 11 cases) and even less than normal (observed in 3 cases) in patients improved by a special diet rich in liver, when the red blood cell count increases to between $4,200,000$ and $6,300,000$ per cubic millimeter.

Under these circumstances, the dispersion of the red blood cell diameters falls and may be well below the upper normal limit, or may remain slightly above normal.

These findings occurred in cases whose red blood cell counts had previously been very low, at which time the cell diameters had all the features associated with pernicious anemia in relapse.

The measurements of the red blood cell diameters of a case of pernicious anemia in "spontaneous" remission, when the red blood cell count was $3,900,000$ per cubic millimeter, showed the mean diameter to be close to the upper normal limit, but the dispersion was slightly above normal ( 1.47 micron). Two cases treated by the special diet for a few weeks showed a rapid increase in their red blood cells to just below $4,000,000$ per cubic millimeter, at which time the size of the red blood cells showed all the features associated with pernicious anemia in relapse.

Measurements of the diameters of the red blood cells were made repeatedly in nine cases of chronic myelogenous leukemia and two of subacute aleukemic myelogenous leukemia. Usually, the red blood cells were found of a size typical of "secondary" anemia. In one case of each type the red blood cell picture simulated that of pernicious anemia in relapse, therefore a distinct macrocytosis appeared during the latter part of the disease. 


\section{BIBLIOGRAPHY}

1. Price-Jones, C.: Brit. Med. Jour., 1910, ii, 1418. The Variation in the Sizes of Red Blood Cells.

2. Price-Jones, C.: Jour. Path. and Bact., 1922, xxv, 487. The Diameters of Red Cells in Pernicious Anemia and in Anemia Following Hemorrhage.

3. Price-Jones, C.: Guy's Hosp. Rep., 1924, lxxiv, 10. Anisocytosis with Special Reference to Pernicious Anemia.

4. Hurst, A. F.: Brit. Med. Jour., 1924, i, 93. An Address on Addison's (Pernicious) Anemia and Subacute Combined Degeneration of the Spinal Cord.

5. Hampson, A. C., and Shackle, J. W.: Guy's Hosp. Rep., 1924, lxxiv, 193. Megalocytic and Non-Megalocytic Anemias.

6. Grosh, L. C., and Stifel, J. L.: Arch. Int. Med., 1925, xxvi, 874. The Diameter of Red Blood Cells in the Differentiation of Anemias.

7. Bell, J. R., Thomas, J. K., and Means, J. H.: Jour. Clin. Invest., 1926, iii, 229. Studies on Red Cell Diameter. I. In Health and in Pernicious Anemia.

8. Minot, G. R., and Murphy, W. P.: Jour. Amer. Med. Assoc., 1926, lxxxvii, 470. Treatment of Pernicious Anemia by a Special Diet. 